\title{
Synthesis and Electrical Conducting Behaviour of Resin Derived from 2, 6 -Diaminopyridine and Terphthalic Acid
}

\author{
DARSHANA URADE ${ }^{\mathrm{a}}$, VINAY HIWASE ${ }^{\mathrm{b}}$ and ASHOK KALAMBE ${ }^{\mathrm{a}}$ \\ ${ }^{a}$ Department of Chemistry, Institute of Science, Nagpur-440 010 (MS), India \\ ${ }^{\mathrm{b}}$ Arts, Commerce and Science College, Arvi, Dist- Wardha (MS)-442201, India \\ vvhiwase@gmail.com
}

Received 13 June 2012 / Accepted 7 July 2012

\begin{abstract}
The resin DAPT was derived by condensing 2, 6-diaminopyridine $(0.1 \mathrm{M})$ and terphthalic acid $(0.1 \mathrm{M})$ in presence of DCC (Dicyclohexylcarbodiimide). The materials were characterized by using elemental analysis, ${ }^{1} \mathrm{H}$ NMR, ${ }^{13} \mathrm{C}$ NMR, FT-IR and UV-Vis spectra. The molecular weight of resin was determined by non aqueous conductometric titration. In the present paper, electrical conductivity properties of the resin DAPT was studied over a wide range of temperatures. The conductivity of DAPT was found to be in the range 0.1379 to $0.1583 \mu \mathrm{S} \mathrm{cm}^{-1}$ for temperature range $333-423 \mathrm{~K}$. The activation energy of conduction for DAPT was found to be $0.7692 \mathrm{kJmol}^{-1}$.
\end{abstract}

Keywords: Wilson's law, Electrical conductivity, Polycondensation, Copolymer, Resin, Semiconductor

\section{Introduction}

Semiconductors are the most important ingredients of modern electronics. The concerted research effort was carried out to aim at developing organic materials that would possess the good electrical properties as the inorganic semiconductors ${ }^{1}$. In fact conductivity depends upon the external conditions such as temperature, humidity, pressure, thickness of samples as well as its chemical structure ${ }^{2}$. Semiconducting polymer have been the subjects of study for many decades for day to day application product, such as corrosion protection and antistatic coatings, in biosensors for coupling of electron transfer, fabrication of electrochemical windows and gas sensors, development of individual electronic devices and whole integrated circuits ${ }^{3-7}$. Electrically conducting polymer resins are one of the important points of current interest in solid state physics and chemistry.

2, 6 Diaminopyridine was used in flurometric studies of novel photoactive polyamide ${ }^{8}$. The derivatives of pyrene, other condensed aromatic hydrocarbons and some heteroaromatic hydrocarbons such as pyrazoline are more considerable in the preparation of photoluminescence polymers ${ }^{9}$. Many coworkers reported the use of 2, 6 diaminopyridine in synthesis macro cyclic ligand for chelation with metal ions such as $\mathrm{Ni}(\mathrm{II}), \mathrm{Cu}(\mathrm{II}), \mathrm{Cr}(\mathrm{III})$, $\mathrm{La}(\mathrm{III}), \mathrm{Pb}(\mathrm{II}), \mathrm{Cd}(\mathrm{II})$ and $\mathrm{Zn}(\mathrm{II})$ which obviously open up fascinating area of research in 
coordination chemistry ${ }^{10-11}$. Masram reported the synthesis and electrical properties of resins. The electrical resistivities of 2-hydroxyaceto-phenoneoxime-thioureatrioxane resin were reported, these polymers ranked as semiconductors ${ }^{12}$.

In this connection many researchers have made attempt to improve the conducting property by changing the composition of monomers by deposition of conducting polymers on the surface copolymer to satisfy electrical properties ${ }^{13-15}$. Recently Hiwase et al. have characterized $p$-hydroxybenzaldehyde-resorcinol-formaldehyde and $p$-hydroxyacetophenonehexamine-formaldehyde ${ }^{16-17}$. Dharkar et al. studied the conductivities of melamine-anilineformaldehyde terpolymer resins and its polychelates. The activation energy values were found to be in range of 0.847 to $1.156 \mathrm{eV}^{18}$. Kushwaha et al. reported semiconducting behavior of resin derived from $p$-Nitrophenol, Resorcinol and Formaldehyde and Kapseet al. carried out the study of terpolymer resin $p$-hydroxyacetophenone -quinhydrone -melamine for its semiconducting property. The DC conductivity of sample was determined by two probe method ${ }^{19-20}$. The present paper deals with the structural analysis of newly synthesized copolymeric DAPT resin and its electrical conducting behavior is reported.

\section{Experimental}

Chemicals were obtained from Merck, Qualigens and S.D. Fine in AR and chemically pure grade.

\section{Synthesis of DAPT copolymer}

The DAPT copolymer was prepared by condensing 2,2 diaminopyridine $(0.1 \mathrm{M})$ and terphthalic acid $(0.1 \mathrm{M})$ at $70-75^{\circ} \mathrm{C}$. In oil bath for 9.00 hours with intermittent shaking. The pale white colored product so obtained was repeatedly washed with hot water to remove unreacted materials. The copolymer was dried and powdered. The product was washed with $0.1 \mathrm{~N} \mathrm{HCl}$ to remove unreacted 2, 6- diaminopyridine followed by several washing with hot water. It was further purified by dissolving in $2 \% \mathrm{NaOH}$ then filtered and reprecipitated by gradual drop wise addition of $1: 1 \mathrm{HCl}$ with constant and rapid stirring in order to avoid lump formation. The DAPT copolymer so obtained was washed several times with hot deionized water and dried in vacuum. The purified copolymer washed, finely ground to pass through 300 mesh size sieves and kept in a vacuum over silica gel. The yield of the copolymer was found to be about $74 \%$. The reaction scheme for synthesis of DAPT is shown in Figure 1 (Table 1).
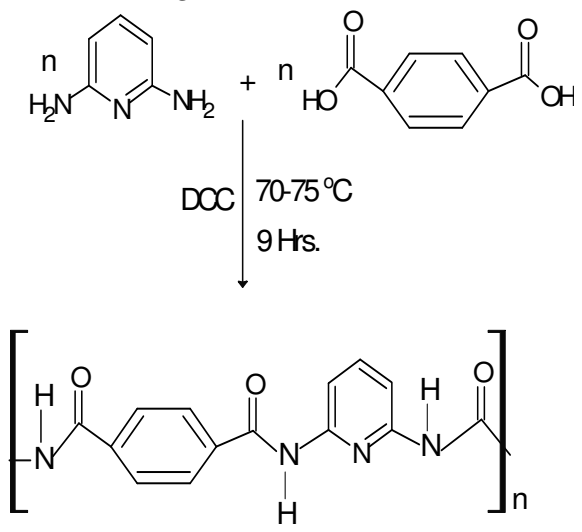

Figure 1. Reaction scheme for copolymer 2, 6-Diaminopyridine - terphthalic acid copolymer (DAPT) 
Table 1. Synthetic details of DAPT resin

\begin{tabular}{cc}
\hline Parameters/conditions & Specifications \\
\hline Copolymeric ligand & DAPT \\
2,2 diaminopyridine & $0.1 \mathrm{M}$ \\
Terphthalic acid & $0.1 \mathrm{M}$ \\
Catalyst (DCC) & $10 \mathrm{~g}$. \\
React.Temp & $70-75^{\circ} \mathrm{C}$ \\
Time & $9.0 \mathrm{~h}$ \\
Yield & $74 \%$ \\
\hline
\end{tabular}

\section{Results and Discussion}

Elemental analysis and molecular weight of DAPT resin

The elemental analysis $(\mathrm{C}, \mathrm{H}$ and $\mathrm{N})$ of copolymeric resin was carried out at Sophisticated Analytical Instrumental Facility (SAIF), Indian institute of Technology (IIT) Bombay. The average degree of polymerization of resin sample was determined by titrating $25 \mathrm{~mL}$ of $0.1 \%$ solution of resin in DMF against $0.1 \mathrm{M} \mathrm{KOH}$ solution in absolute alcohol, conductometrically. The conductance was plotted against the miliequivalents $\mathrm{KOH}$ per $100 \mathrm{~g}$. of resin. The inspection of plot revealed that there were many breaks in the plot. The DP was calculated by using following equation,

$$
\overline{D P}:=\frac{\text { Milliequivalent of base required for complete neutralisation }}{\text { Milliequivalent of base required for smallest interval }}
$$

The molecular weight of resin was determined by using following relation,

$$
\mathrm{Mn}=\mathrm{DP} \times \text { Molecular weight of the repeating unit }
$$

The repeating unit weight was obtained from elemental analysis. The elemental analysis and molecular weight determination data of DAPT resin are given in following Table 2.

\begin{tabular}{|c|c|c|c|c|c|c|c|c|c|c|}
\hline \multirow[b]{2}{*}{ Resin } & \multicolumn{2}{|c|}{$\% \mathrm{C}$} & \multicolumn{2}{|c|}{$\% \mathrm{H}$} & \multicolumn{2}{|c|}{$\% \mathrm{~N}$} & \multirow[b]{2}{*}{ DP } & \multirow[b]{2}{*}{$\begin{array}{l}\text { Mol. } \\
\text { weight } \\
\left(M_{n}\right)\end{array}$} & \multirow{2}{*}{$\begin{array}{l}\text { Mol. } \\
\text { Formula of } \\
\text { repeating } \\
\text { unit }\end{array}$} & \multirow{2}{*}{$\begin{array}{l}\text { Molecular } \\
\text { Weight of } \\
\text { repeating } \\
\text { unit }\end{array}$} \\
\hline & $\bar{U}$ & $\begin{array}{l}\vec{\Xi} \\
\text { Oे } \\
\text { I. }\end{array}$ & Uే & $\begin{array}{l}\vec{\Xi} \\
\text { Oे } \\
\text { I. }\end{array}$ & $\tilde{U}$ & $\begin{array}{l}\vec{O} \\
\text { Oे } \\
\text { I. }\end{array}$ & & & & \\
\hline DAPT & 59.57 & 58.94 & 3.54 & 3.43 & 19.85 & 19.65 & 17 & 4794 & $\mathrm{C}_{14} \mathrm{H}_{10} \mathrm{~N}_{4} \mathrm{O}_{3}$ & 282 \\
\hline
\end{tabular}

Table 2. Elemental Analysis and molecular weight determination of DAPT resin

\section{Spectral analysis}

FTIR spectra of synthesized copolymeric resins were recorded at Department of Pharmacy; RTM Nagpur University, Nagpur Using FT-IR spectrophotometer Shimadzu, Model No8101A. ${ }^{1} \mathrm{H}$ and ${ }^{13} \mathrm{C}$ NMR spectrum of copolymeric resin using DMSO-d ${ }^{6}$ solvent was scanned on BRUKER AC II 400 NMR spectrophotometer SAIF, Punjab University, Chandigarh. UV-VIS spectra of copolymer resin in DMSO solvent recorded by UV-VIS Double Beam Spectrophotometer Shimadzu, Model No-1701 fitted with automatic pen chart recorder at Department of Pharmacy, RTM Nagpur University, Nagpur.

\section{FTIR spectrum data of DAPT resin}

FT- IR spectrum is shown in Figure 2 and related data ${ }^{21-22}$ is tabulated in Table 3. 


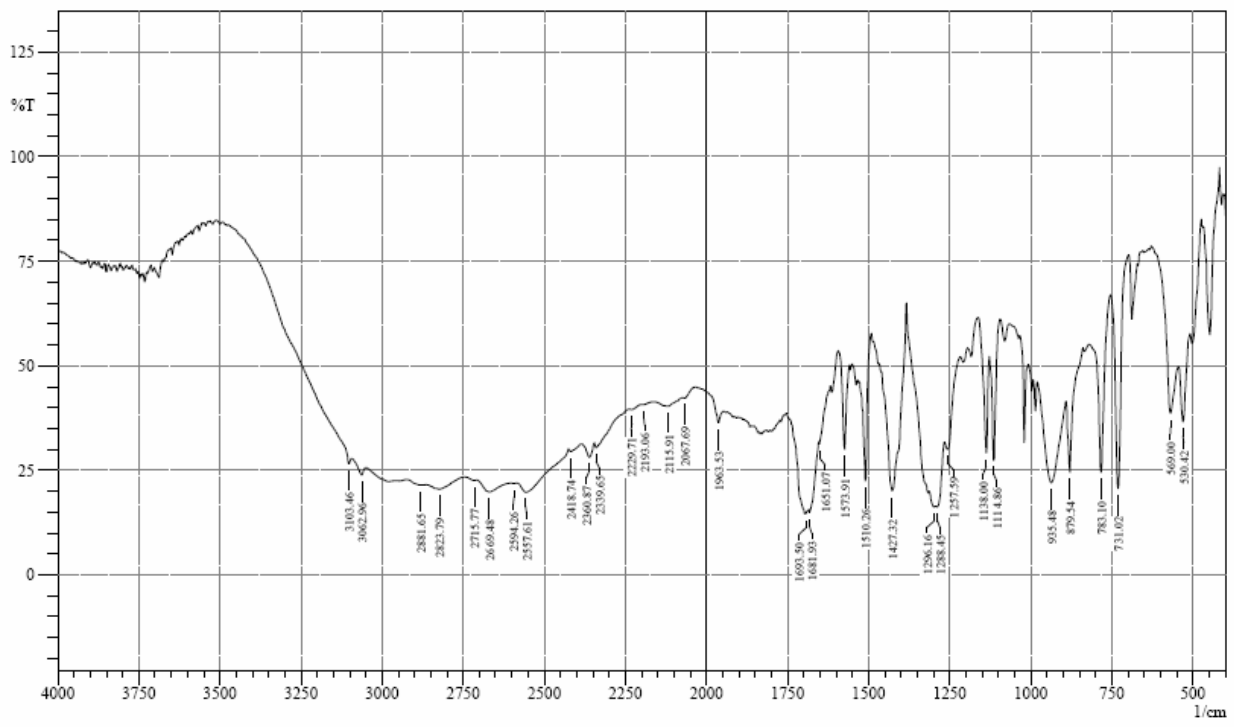

Figure 2. FTIR spectrum of DAPT resin and peak assignments

Table 3. FTIR Spectrum data of DAPT resin

\begin{tabular}{|c|c|c|c|}
\hline $\begin{array}{l}\text { Frequency } \\
\text { in } \mathrm{cm}^{-1}\end{array}$ & $\begin{array}{l}\text { Nature of fragment } \\
\text { assigned }\end{array}$ & Frequency in $\mathrm{cm}^{-1}$ & $\begin{array}{c}\text { Nature of fragment } \\
\text { assigned }\end{array}$ \\
\hline 3103 & NH Str. in sec. amide & 1510 & Sec. amide (II) band \\
\hline 3062 & $\mathrm{CH}$ Aromatic str. & 1427 & $\begin{array}{c}\mathrm{C}=\mathrm{N} \text { Str. (pyridine } \\
\text { ring) }\end{array}$ \\
\hline $2339,2360,2418$ & Overtone bands & 1296,1288 & C-N Str. in -CONH- \\
\hline 1691 & $\mathrm{C}=\mathrm{O}$ amide $(\mathrm{I})$ band & 1020,997 & $\begin{array}{c}\mathrm{C}-\mathrm{O} \text { deformation in - } \\
\mathrm{CONH}-\end{array}$ \\
\hline 1651 & $\begin{array}{c}\mathrm{C}=\mathrm{C} \\
\text { (Pyridine ring Str.) }\end{array}$ & 879 & $\begin{array}{l}1,4 \text { disubstituted } \\
\text { aromatic ring }\end{array}$ \\
\hline 1573 & $\mathrm{~N}-\mathrm{H}$ deformation & $1114,1112,, 783,731$ & $\begin{array}{l}\text { 1,6 disubstituted } \\
\text { pyridine ring }\end{array}$ \\
\hline
\end{tabular}

The absorption band at $3103 \mathrm{~cm}^{-1}$ was assigned to $\mathrm{N}-\mathrm{H}$ stretching in secondary amide. The broad band at $3062 \mathrm{~cm}^{-1}$ was assigned to $\mathrm{C}-\mathrm{H}$ aromatic streching. The absorption at $1691 \mathrm{~cm}^{-1}$ was assigned to $>\mathrm{C}=\mathrm{O}$ amide (I) band. Further low value of this band was supported to formation of polyamide. The band at $1510 \mathrm{~cm}^{-1}$ was due to the coupling of $\mathrm{N}-\mathrm{H}$ bending and $\mathrm{C}-\mathrm{N}$ streching absorption (amide II band) indicates the presence of secondary amide group (amide linkages). The sharp band displayed at $1573 \mathrm{~cm}^{-1}$ was assigned to $\mathrm{N}-\mathrm{H}$ deformation. The band display at $1651 \mathrm{~cm}^{-1}$ was assigned to $\mathrm{C}=\mathrm{C}$ in Pyridine ring. The absorption at $1427 \mathrm{~cm}^{-1}$ was attributed to $\mathrm{C}=\mathrm{N}$ streching in Pyridine ring. The bands appeared at $1296 \mathrm{~cm}^{-1}$ and $1288 \mathrm{~cm}^{-1}$ were attributed to C-N stretching in secondary amide. The peaks at $1020,997 \mathrm{~cm}^{-1}$ were due to C-O deformation in-CONH-. The peaks at $879 \mathrm{~cm}^{-1}$ was assigned 1, 4 disubstituted aromatic rings. The peaks at $1114,1112,783,731 \mathrm{~cm}^{-1}$ was assigned to 1,6 disubstituted pyridine rings.

\section{${ }^{1} \mathrm{H} N M R$ and ${ }^{13} \mathrm{C}$ NMR spectrum of DAPT resin}

The ${ }^{1} \mathrm{H}$ NMR and ${ }^{13} \mathrm{C}$ NMR spectrum is shown in Figure 3 and Figure 4 respectively. 


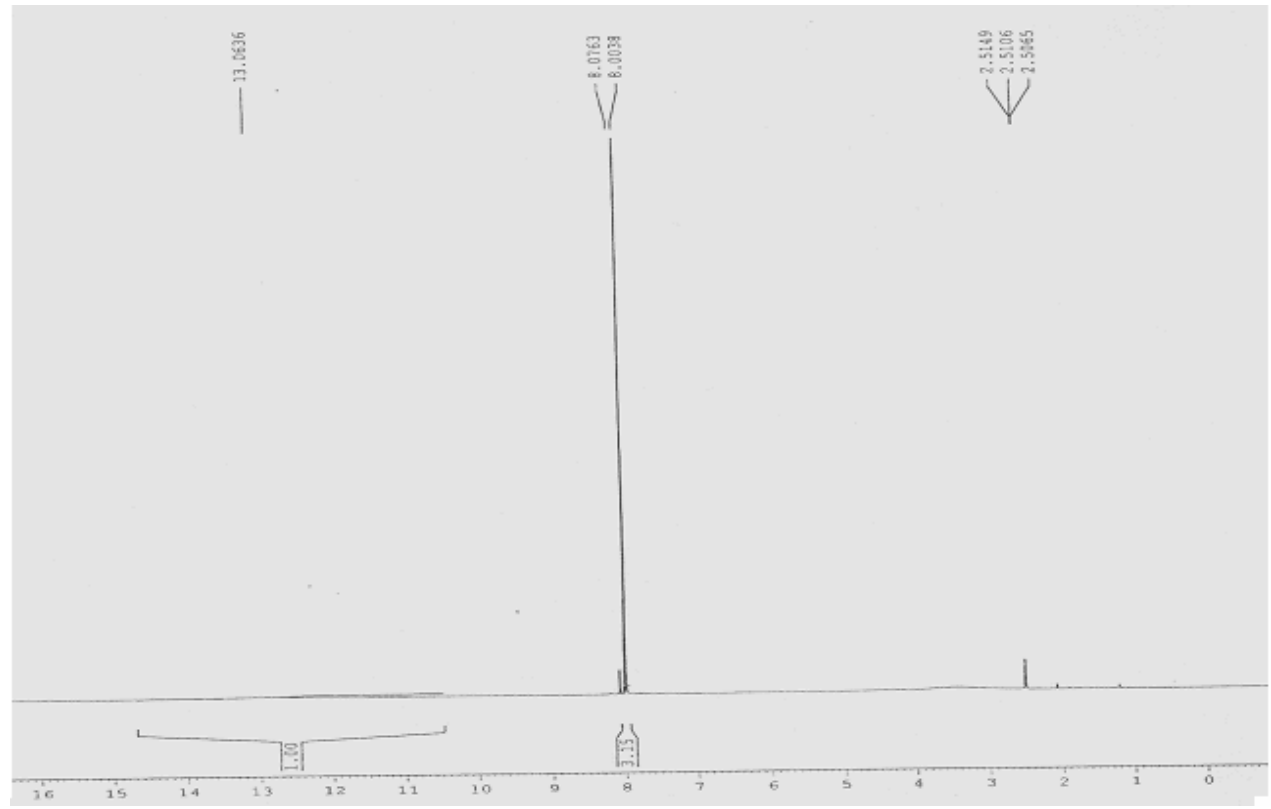

Figure 3. ${ }^{1} \mathrm{H}$ NMR spectrum of DAPT resin

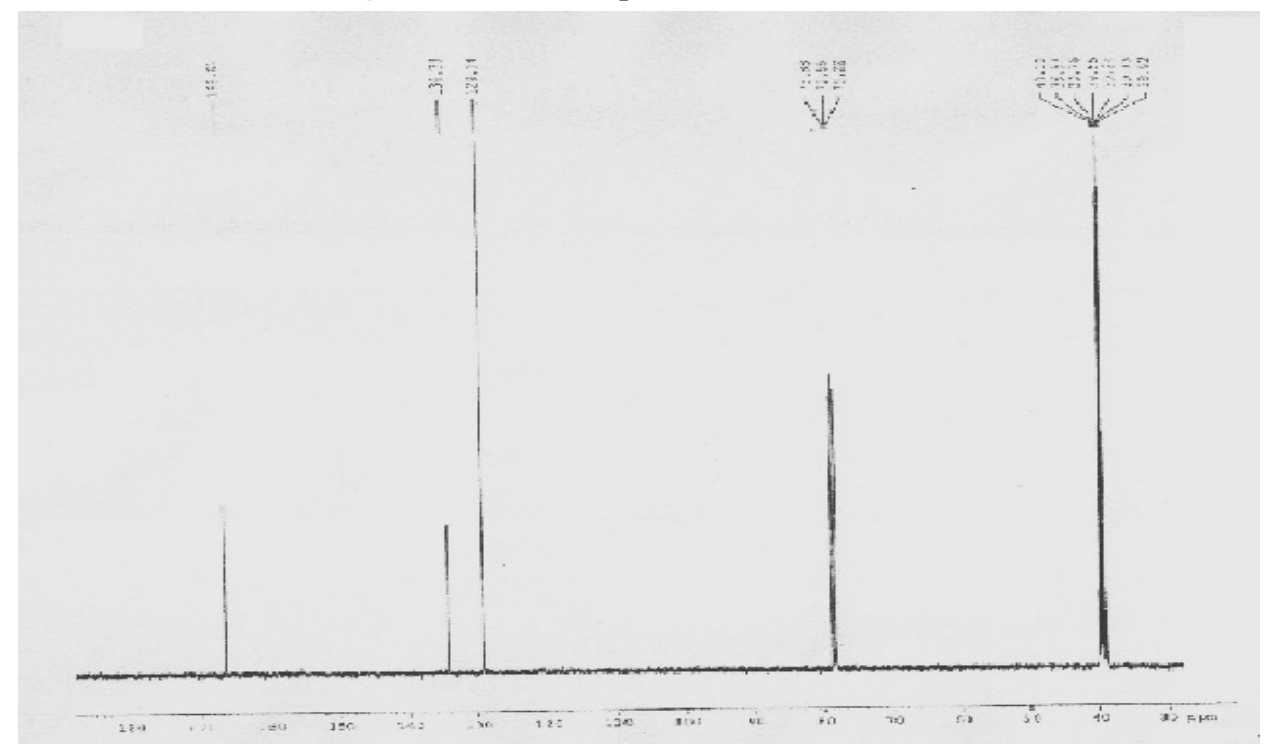

Figure 4. ${ }^{13} \mathrm{C}$ NMR spectrum of DAPT resin

In ${ }^{1} \mathrm{H}$ NMR spectrum of DAPT copolymer the signals at $8.0 \delta \mathrm{ppm}$ was attributed to $\mathrm{N}-\mathrm{H}$ in amide linkages. The signal at $8.07 \delta \mathrm{ppm}$ was due to proton in pyridine ring. The signal at $2.50 \delta \mathrm{ppm}$ was due to DMSO solvent. In ${ }^{13} \mathrm{C}$ NMR spectrum of DAPT copolymer the signal at $129.14 \delta \mathrm{ppm}$ was assigned to carbon in terphthalic acid moiety. Signal at $134.33 \delta \mathrm{ppm}$ was due to carbon in pyridine ring. Signal at $166 \delta \mathrm{ppm}$ was attributed to $>\mathbf{C}=\mathrm{O}$ carbonyl carbon in amide linkages ${ }^{23-24}$. 


\section{$U V$-VIS spectrum of DAPT resin}

The UV-Vis spectrum is shown in the Figure 5. The inspection of UV-Vis spectrum of DAPT resin reveals two types of transition $\pi-\pi^{*}$ and $n-\pi^{*}$ transition. The important UV-Vis absorptions data are tabulated in Table 4.

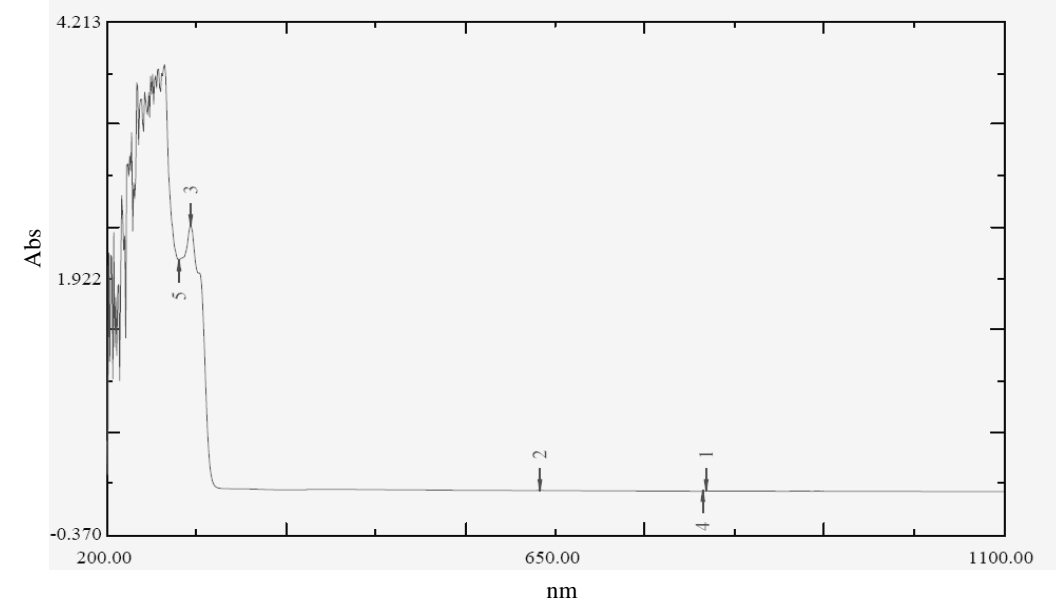

Figure 5. UV-VIS spectrum of DAPT resin

Table 4. UV-VIS data of DAPT resin

\begin{tabular}{cccc}
\hline Resin & Transition & Wavelength $(\mathrm{nm})$ & Group/ moiety assigned \\
\hline & \multirow{3}{*}{$\pi-\pi^{*}$} & 234 & $\mathrm{C}=\mathrm{C}$ Aromatic ring \\
& & 253 & $\mathrm{C}=\mathrm{N}$ Pyridine ring \\
\multirow{2}{*}{ DAPT } & & 267 & $\mathrm{C}=\mathrm{C}$ Pyridine ring \\
& $\mathrm{n}-\pi^{*}$ & 284 & $\mathrm{C}=\mathrm{O}$ amide group \\
& & 295 & pyridine ring \\
\hline
\end{tabular}

\section{Electrical conductivity of DAPT resin}

The DC conductivities of DAPT resin was studied for wide temperature range. The electrical conductivity as a function of temperature of the polymer was studied. The electrical conductance of polymeric materials depends upon incalculable parameters such as porosity, pressure; method of preparation and atmosphere ${ }^{25-26}$. The powdered samples of DAPT resin was palatalized by hydraulic press at pressure of $17 \mathrm{lb}$ inch $^{-2}$. The surface of pallet was made conducting by applying graphite paste. The diameter and thickness was measured using screw gauge. The solid state conductivity as function of temperature was recorded by two probe method ${ }^{27}$. The plot of $\log \sigma$ versus $1 / \mathrm{T}$ was found to be linear in the temperature range under study, which indicate that the Wilson's exponential law, $\sigma=\sigma^{\circ}$ $\exp ^{(-\mathrm{E} / \mathrm{kT})}$ was obeyed.

Where, k=Boltzmann constant. $\sigma=$ Electrical conductivity at temperature $\mathrm{T}$. $\sigma^{\circ}=$ Electrical conductivity at temperature $\mathrm{T} \rightarrow \infty$. Ea=Activation energy of conduction. The energy of activation (Ea) of electrical conduction of DAPT resin calculated from the slope of the plot. Electrical conductivity plot of DAPT resin is given in Figure 5. Electrical conductivity data of DAPT resin is shown in Table 5. 


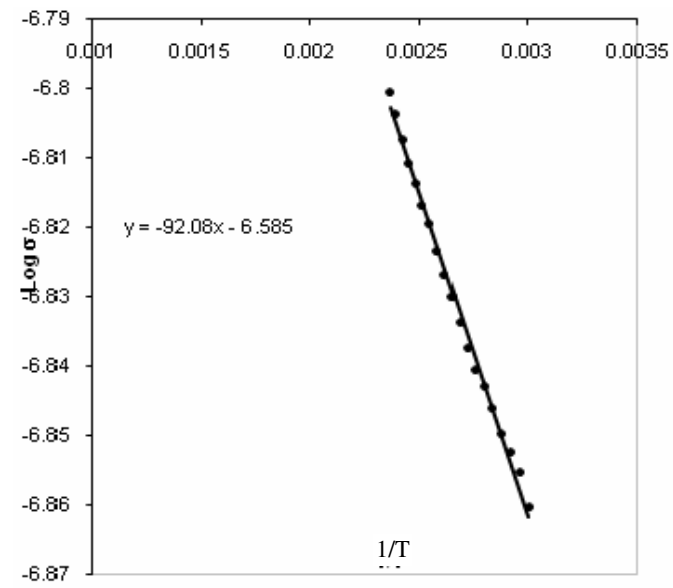

Figure 6. Plot of Electrical conductivity of DAPT resin

Table 5..Electrical conductivity data of DAPT resin

\begin{tabular}{cccc}
\hline Resin & $\begin{array}{c}\text { Temperature } \\
\text { Range }(\mathrm{K})\end{array}$ & $\begin{array}{c}\text { Activation energy } \\
(\mathrm{kJ} \mathrm{mole})^{-1}\end{array}$ & $\begin{array}{c}\text { Activation energy } \\
(\mathrm{eV}) \times 10^{23}\end{array}$ \\
\hline DAPT & $333-423$ & 0.7692 & 2.8906 \\
\hline
\end{tabular}

\section{Conclusion}

The elemental analysis and spectral studies such as UV-VIS, IR, ${ }^{1} \mathrm{H}$ NMR, ${ }^{13} \mathrm{C}$ NMR data is in good agreement to the above assigned tentative structure of DAPT copolymer shown in Figure 2. The plot of $\log \sigma$ versus $1 / \mathrm{T}$ is linear with negative slope hence satisfy with Wilson's equation. Thus the resin shows semiconducting behavior. The plot shows that the conductivity expontially increases with increase in temperature from $333 \mathrm{~K}$ to $423 \mathrm{~K}$. the conductivity values are ranges from 0.1379 to $0.1583 \mu \mathrm{S} \mathrm{cm}^{-1}$ in mentioned temperature range.

\section{Reference}

1. Masram D T, Kariya K P and Bhave N S, Archives App Sci Res., 2010, 2(2), 153-161.

2. $\quad$ Singh H P and Gupta D, Indian J Pure Appl Phys., 1986, 24, 444-447.

3. Gautmann L and Lyons O L E, Org, Semiconductor. John Willey, New York 1967.

4. Genies E M, Syed A A and Tsintavis C, Mol Cryst Liq Cryst., 1985, 121, 181.

5. Dewar J S and Talati A M, J Am Chem Soc., 1964, 86, 1592.

6. Lingala P S, Paliwal L J and Juneja H D, National Seminar on Polymers, Chennai, 1999.

7. Pal T K and Kharat R B, Die Angewandte Macromol Chem., 1989, 173, 55-68.

8. Khoee S, Sadeghi F and Zamani S, Elsevier, J Photochem Photo A: Chem., 2007, 189, 30.

9. Khandar A A, Hosseini-Yazdi S A, Khatamian M, McArdle P and Zarei S A, Polyhedron, 2007, 26, 33-38.

10. Ilhan S, Temel H, Sunkur M and Tegin I, Indian J Chem., 2008, 47A, 560.

11. Pancholi H B and Patel M J, Ind Chem Soc., 1998, 75, 86.

12. Masram D T, Kariya K P and Bhave N S, e-Polymer, 2007, Article no.75. 
13. Matveena E, Carracossa R J and Palomina M, J Appl Polym Sci., 2004, 94, 1752-1758.

14. Umare S S, Borkar A D and Gupta M C, Bull Mater Sci., 2000, 23(3), 235-239.

15. Job A E, Hermann P S, Vaz D O and Mattoso J, J Appl Polym Sci., 2001, 79, 1220.

16. Hiwase V V, Kalambe A B, Khedkar K M and Deosarkar S D, E-J Chem., 2010, 7(1), 287-294.

17. Hiwase V V, Kalambe A B, Umare S S and Khedkar K M, Acta Ciencia Indica, 2007, XXXIIIC(4), 615.

18. Dharkar K P, Ingle S S and Kalambe A B, E-J Chem., 2011, 8(1), 127-130.

19. Kushwaha A D, Hiwase V V and Kalambe A B, Der Pharma Chemica, 2012, 4(1), 557-567.

20. Kapse S K, Hiwase V V and Kalambe A B, J Chem Pharm Res., 2012, 4, 557.

21. Morrison R T and Boyd R N, Organic chemistry Prentice Hall 3-Pub. Co. Pvt. Ltd. 6. Wardlaw G M, Hampl JS, $7^{\text {th }}$ Edn., 2007.

22. Ballamy L J, The IR Spectroscopy of Complex Molecules, John Wiley and Sons. Inc., 142.

23. Li L, Osamu H, Takeshi E and Mitsuru U, High Perfor Poly., 2001, 13, 217.

24. Field L D, Sternell S and Kalman J R, Org, Struct. From spectra, John Willey and Sons, New York, 1969, 2, 299.

25. Masram D T, Karia K P and Bhave N S, Arch Appl Sci Res., 2010, 2(2), 153.

26. Singru R N, Khati V A, Gurnule W B, Zade A B and Dontulwar J R, Anal Bioanal Electrochem., 2011, 3(1), 67.

27. Shahid M Y, Shabana T, Zahoor A and Farid A K, Iranian Poly J., 1998, 7(2), 79-82. 